\title{
Effect of combined irradiation and EGFR/Erb-B inhibition with BIBW 2992 on proliferation and tumour cure in cell lines and xenografts
}

Kristin Gurtner ${ }^{1,2^{*}}$, Nadja Ebert ${ }^{1,2}$, Dorothee Pfitzmann ${ }^{1,2}$, Wolfgang Eicheler ${ }^{1,2}$, Daniel Zips ${ }^{3}$, Michael Baumann ${ }^{1,2,4,5}$ and Mechthild Krause $e^{1,2,4,5}$

\begin{abstract}
Background and purpose: In previous experiments an enhanced anti-proliterative effect of the EGFR/ErbB tyrosine kinase inhibitor (TKI) BIBW 2992 with single dose irradiation was observed in FaDu tumour xenografts. Aim of the present experiment was to determine if this effect can also be seen in combination with a fractionated radiotherapy. Secondly we investigate the efficacy of BIBW 2992 on local tumour control for UT-SCC-15.

Material and methods: Tumour pieces of FaDu, UT-SCC-14, A431, UT-SCC-15 (squamous cell carcinomas) and A7 (glioma) tumour models were transplanted onto the right hind leg of NMRI (nu/nu) nude mice. For evaluation of tumour growth mice were either treated daily orally with BIBW 2992 (30 mg/kg body weight), or carrier up to a final tumour size of $15 \mathrm{~mm}$ or with a fractionated radiotherapy (15f/15d, $30 \mathrm{~Gy}$ ) with simultaneous application of BIBW 2992 or carrier. For local tumour control UT-SCC-15 tumours were treated with a fractionated radiotherapy (30f/6weeks) or received 30f/6 weeks in combination with daily orally BIBW 2992 (22.5 mg/kg b.w.) during RT.

Results: A significant effect on tumour growth time was observed in all tumour models for BIBW 2992 application alone. However, substantial intertumoural heterogeneity could be seen. In the UT-SCC-14, UT-SCC-15 and A431 tumour models a total regression of the tumours and no recurrence during treatment time (73 days) were determined where as for the A7 tumour only a slight effect was noticeable. For the combined treatment of fractionated radiotherapy (15f/15d) and BIBW 2992 administration a significant effect on tumour growth time was seen compared to irradiation alone for A7, UT-SCC-15 and A431 (ER 1.2 - 3.7), this advantage could not be demonstrated for FaDu and UT-SCC-14. However, the local tumour control was not altered for the UT-SCC-15 tumour model when adding BIBW 2992 to fractionated irradiation (30f/6weeks).

Conclusion: A heterogeneous effect on tumour growth time of BIBW 2992 alone as well as in combination with fractionated irradiation could be demonstrated for all tumour models. However, the significant effect on tumour growth time did not translate into an improvement of local tumour control for the UT-SCC-15 tumour model.
\end{abstract}

Keywords: Combined treatment, Molecular targeting, EGFR/ErbB-inhibition, Fractionated irradiation, Local tumour control, BIBW 2992

\footnotetext{
* Correspondence: kristin.gurtner@uniklinikum-dresden.de

${ }^{1}$ Department of Radiation Oncology, UniversityHospital C.G. Carus,

Fetscherstr. 74, 01307 Dresden, Germany

${ }^{2}$ OncoRay - National Centerfor Radiation Research in Oncology, Medical

Faculty and University Hospital Carl Gustav Carus, TechnischeUniversität and

Helmholtz-Zentrum Dresden -Rossendorf, Dresden, Germany

Full list of author information is available at the end of the article
} 


\section{Introduction}

Overexpression of the epidermal growth factor receptor (EGFR) on tumour cells has been shown to increase chemo- and radioresistance and therefore is associated with a poor outcome [1-3]. Inhibition of the EGFR in combination with radiotherapy has become a promising strategy to overcome this resistance. While anti-EGFR antibodies like cetuximab have the potential to prolong tumour growth and improve local tumour control when applied simultaneously to irradiation [4-10], for tyrosine kinase inhibitors (TKI), e.g. Erlotinib, the prolongation of tumour growth time did not translate into improved curative effects $[1,8,11]$. Clinical evaluation of EGFR-TK inhibition in combination with chemo- or radiotherapy revealed also heterogeneous effects $[1,12]$. One reason for the rather minor effects of TKI on local tumour control could be that through heterodimerisation with other receptors of the EGFR-family, e.g. ErbB2, signaltransduction is still possible and therefore exclusively blocking the EGFR-TK is not sufficient [13-15]. Targeting more than one receptor of the EGFR-family might therefore show a therapeutic benefit.

BIBW 2992 is an irreversible ErbB-family (EGFR/ErbB2/ ErbB4) inhibitor, which in previous experiments demonstrated a significant prolongation of tumour growth time in a combined setting with single dose irradiation in $\mathrm{FaDu}$ tumour xenografts. In vitro but not in vivo a radiosensitizing effect could be shown for this tumour model. The antiproliferative effects are in line with a clear G0/G1 arrest of the tumour cells [16]. Based on these findings, the aim of the current study was to investigate the effect of BIBW 2992 with or without fractionated irradiation on tumour growth in five different human tumour xenografts (A7, A431, FaDu, UT-SCC-14 and UT-SCC-15). Consecutively, after these first experiments a local tumour control experiment was performed in the tumour model with the greatest effect on tumour growth time (UT-SCC-15).

\section{Material and methods}

\section{Animals and tumours}

7 to14-week-old male and female NMRI (nu/nu) mice from the specific pathogen-free animal breeding facility of the Experimental Center of the Medical Faculty Carl Gustav Carus, Technische Universität Dresden were used for the experiments. The facility veterinarians checked the microbiological status of the animals regularly. The experiments and animal facilities were approved according to the German animal welfare regulations. Water ad libitum and a commercial laboratory animal diet were provided for the animals. A constant temperature of $26^{\circ} \mathrm{C}$, daylight in addition to a $12 \mathrm{~h}$ light-12h dark electric cycle (light-on time 07.00 a.m.) and a relative humidity of 50-60\% were supplied within the animal room. A whole-body irradiation $2-5$ days before tumour transplantation with 4 Gy using $200 \mathrm{kV} \mathrm{X}$-rays $(0.5 \mathrm{~mm} \mathrm{Cu})$ at a dose rate of about $1 \mathrm{~Gy} / \mathrm{min}$ was given for further immunosuppression of the animals.

Four established human squamous cell carcinoma lines (FaDu, UT-SCC-14, UT-SCC-15, A431) and a glioma cell line (A7) were used in this study. UT-SCC-14 and UT-SCC-15 were established by Prof. Reidar Grenman (University of Turku, Finland). UT-SCC-14 $[17,18]$ was derived from a squamous cell carcinoma of the tongue, UT-SCC-15 [17] is a tumour cell line originating of a recurrent tumour of the tongue. $\mathrm{FaDu}$ is an undifferentiated tumour of the hypopharynx [6,17,19-21], originally obtained from the American Type Culture Collection (ATCC) that differs from the original tumour by an additional loss of heterozygosity in the p53 gene (TP53) [22]. A431 is a squamous cell carcinoma of the female genitales (DSMZ, German Collection of Microorganisms and Cell Cultures, Braunschweig, Germany) and A7 is a glioblastoma cell line (Gray Cancer Institute, Mount VernonHospital, Northwood, Middlesex, Great Britain). A cryostock of tumour pieces of all tumour models is kept in Dresden. Out of the cyrostock, generated tumours were passaged in nude mice over 2 generations. The origin of the tumours was validated during passaging by histological examinations, short tandem repeats analysis (microsatellites), and lactate dehydrogenase isoenzyme pattern. Additional histological examinations, evaluations of the volume doubling time and of the lactate dehydrogenase isoenzyme pattern were carried out in parallel to the experiments to ensure constancy of the models and exclude murinization. No or very little residual immune response in nude mice was shown for 4 of the 5 cell lines in previously reported studies [17,23-26]. For A431 tumours local control experiments with and without whole body irradiation were performed revealing no immune response reaction against this tumour line by nude mice. The $\mathrm{TCD}_{50}$ for single dose irradiation under clamp conditions with whole body irradiation was 58.6 Gy [95\% CI: 60;174] and without whole body irradiation 67.8Gy [95\% CI: $51 ; 277](\mathrm{p}=0.577)$.

In the experiments, tumour pieces of 1-2 mm diameter were transplanted subcutaneously into the right hind leg of anesthetised (16 mg/kg body weight (b.w.) xylazine [intraperitoneal, i.p.] and $120 \mathrm{mg} / \mathrm{kg}$ b.w. ketamine [i.p.]) animals. All procedures for tumour transplantation have been described previously in detail [8,26-28].

Animal welfare approval number: 24D-9168.11-1/ 2006-20.

\section{Administration of BIBW 2992}

BIBW2992, a second generation tyrosine kinase inhibitor of the epidermal growth factor receptor (EGFR) family 
binds irreversibly to the intracellular tyrosine kinase of the EGFR and ErbB2 and ErbB4-receptor [29,30]. Its effectiveness in vitro and in vivo has been shown to be greater than that of the first generation TKIs (e.g. erlotinib) [30] and resistance to first generation EGFR inhibitors could be overcome in certain cell lines by BIBW 2992 [29]. BIBW 2992 was kindly supplied by Boehringer Ingelheim RCV, Vienna Austria.

For evaluation of the drug effect alone, carrier or BIBW 2992 was administered daily orally at a concentration of $30 \mathrm{mg} / \mathrm{kg} \mathrm{b}$. w. up to the final size of the tumour (one diameter reaching $15 \mathrm{~mm}$ ). Within the combined treatment, carrier or BIBW 2992 were only given simultaneously during fractionated irradiation using the same application and concentration schedule mentioned above, with a 4 hour interval before each irradiation fraction. For the local control experiment a lower BIBW 2992 concentration $(22.5 \mathrm{mg} / \mathrm{kg}$ b.w.) was administered due to observed toxicity within the previous experiments.

\section{Local tumour irradiation}

Local tumour irradiation was carried out under ambient conditions to air-breathing animals without anaesthesia (200 kV X-rays, $0.5 \mathrm{~mm} \mathrm{Cu}$, single beam, dose rate $\sim 1$ Gy/min, source to skin distance $42 \mathrm{~cm}$ ). Specially designed jigs were able to hold 5 animals for simultaneous irradiation. The tumour-bearing leg was held positioned in the irradiation field while mice were immobilized in a plastic tube which was fixed on a lucite plate by a footholder distal to the tumour.

\section{Experimental design}

The first experiment was divided into 2 arms (Figure 1): in arm (A) animals were treated with either carrier or BIBW 2992 orally daily up to the final size of the tumour (14-16 animals per group). In the second arm (B) tumours were additionally irradiated with 15 fractions applying one fraction per day (14-16 animals per group). Carrier or BIBW 2992 were given 4 hours before each irradiation fraction without continuation after the end of irradiation.

For the local tumour control experiment $(\mathrm{C})$, the UT-SCC-15 tumour model was selected as the best responding model regarding tumour growth time (Figure 2). UT-SCC-15 tumours were irradiated with 30 fractions within 6 weeks up to total irradiation doses of 20 to 120 Gy ( 9 dose groups, 6-8 animals per dose group). As in the first experiment, carrier or BIBW 2992 were applied 4 hours before each irradiation fraction and continued over the irradiation-free weekends, but not after the end of irradiation.

Tumour volumes for both experiments at start of treatments were approximately $100 \mathrm{~mm}^{3}$ (median volume $\left.112 \mathrm{~mm}^{3}, 10-90 \%=100-160 \mathrm{~mm}^{3}\right)$.

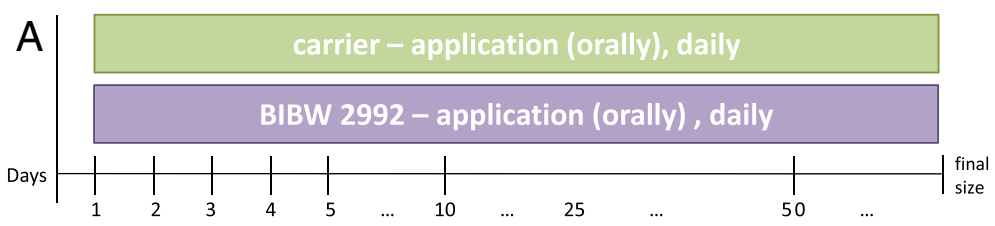

Irradiation (30 Gy)

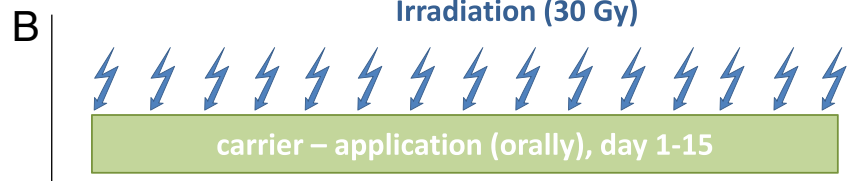

BIBW 2992 - application (orally), day 1-15

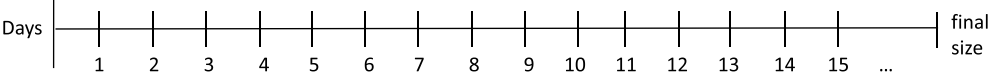

Irradiation (20 - 120 Gy)

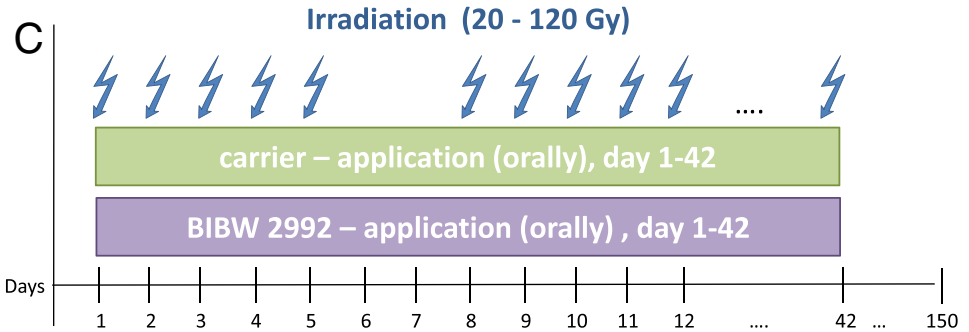

Figure 1 Experimental design. A) Application of either carrier or BIBW 2992 up to the final size of the tumour. B) Fractionated irradiation (15f; total dose $30 \mathrm{~Gy}$ ) in combination with carrier or BIBW 2992 during irradiation time. C) Fractionated irradiation (30f/6 weeks/total doses between 20 and $120 \mathrm{~Gy}$ ) in combination with carrier or BIBW 2992 during irradiation time. 


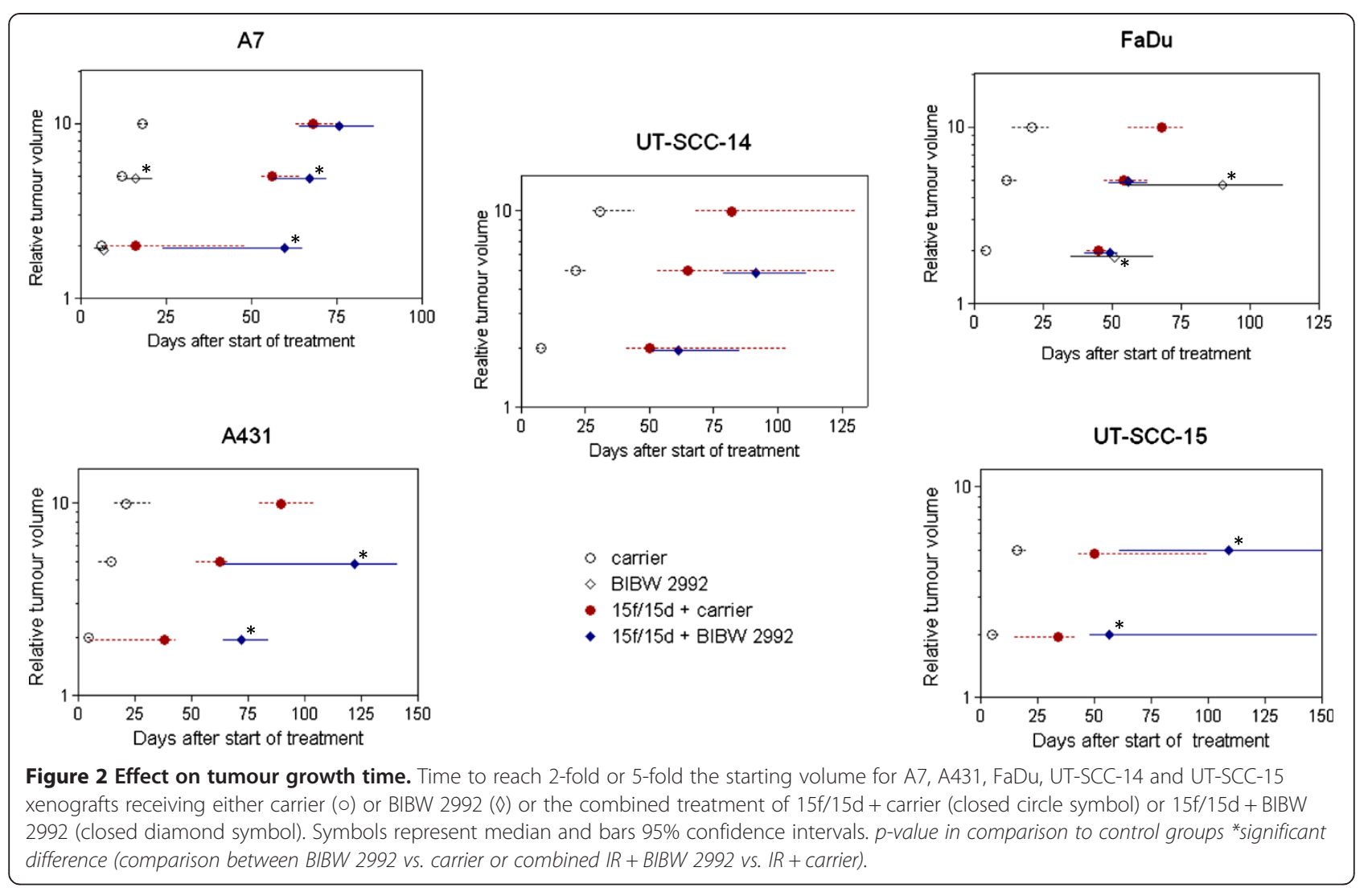

\section{Follow-up}

Animals were observed up to final tumour size (mean diameter exceeded $15 \mathrm{~mm}$ ), until day 150 after the end of treatment or until death. For UT-SCC-15 tumours that were evaluated for local tumour control, it has been shown before that almost all recurrences occur within that followup time after radiotherapy [17]. In the local control experiment $96 \%$ of 46 recurrences after irradiation occurred before day 126, the last recurrence was seen at day 130 . Animals that appeared to suffer needed to be killed before these endpoints were reached.

\section{Determinations of tumour volume and tumour growth time}

Tumour diameters were determined twice per week. With the formula for the rotational ellipsoid $V=\pi / 6^{*} \mathrm{a}$ * $\mathrm{b}^{2}$, where $\mathrm{a}$ is the longest and $\mathrm{b}$ is the perpendicular shorter tumour axis, tumour volumes were calculated. For each treatment arm the median tumour volumes and their standard errors were computed as a function of time after start of treatment. Evaluations were stopped when $<50 \%$ of the animals of each treatment arm were alive. From individual growth curves the median tumour growth time was calculated as the time that a regrowing tumour needed to reach 2 and 5 fold of the starting volume $\left(\mathrm{GD}_{\mathrm{V} 2}, \mathrm{GD}_{\mathrm{V} 5}\right)$. Enhancement ratios (ER) were computed as the quotient of a GD value of BIBW 2992 treated tumours and the GD value in the carrier treated group.

Dose-response curves for local tumour control and $\mathrm{TCD}_{50}$ values

150 days after end of irradiation tumour control rates were calculated for each dose group after correction for censored animals according to the method given by Walker and Suit [31]. When an increased volume for at least three consecutive measurements was observed after passing a nadir, recurrences were scored. Animals that died from tumourindependent reasons and therefore could not be followed up, were censored at the last day of measurement. When death occurred before day 20 after end of treatment animals (without recurred tumour) were excluded from the analysis. Animals with local failure before death were not excluded from the analysis but counted as failure. Based on the individual tumour control data a binary (cure/failure) model was used to fit tumour control probability (TCP) curves. The TCP was modeled using the logit model

$$
\mathrm{TCP}=1 /[1+\exp (-f(x, \beta)]
$$

where $x=$ vector of covariates that define the treatment, $\beta=$ vector of parameters describing radiosensitivity of 
the tumours, and $f$ is a (possibly nonlinear) function of these. Parameters were estimated using maximum likelihood as implemented in STATA 7.0 software (STATA Corporation, College Station TX). Quoted confidence limits are asymptotic estimates from the results of the likelihood fits. Comparison of maximum likelihood fits was performed using the likelihood ratio test. Tumour control dose $50 \%\left(\mathrm{TCD}_{50}\right)$ at day 150 after end of irradiation and associated dose-response curve were determined from:

$$
f(D, \beta)=\beta_{1}\left(1-D / \beta_{2}\right) \text { where } \beta_{1} \text { is a constant and } \mathrm{TCD}_{50}=\beta_{2}
$$

\section{Cell survival in vitro}

Tumour cells of the different cell lines were grown in Dulbeccos modified Eagle's medium with glutamine, 10\% fetal calf serum, $1 \mathrm{mM}$ pyruvate, $1 \%$ non-essential amino acids, $20 \mathrm{mM}$ HEPES and 1\% Penicillin-Streptomycin at $37^{\circ} \mathrm{C}$ ( $5 \% \mathrm{CO}_{2}, 95 \%$ humidity) in $25 \mathrm{~cm}^{2}$ tissue culture flasks. For the A7 tumour model MEM-EARLE with 10\% fetal calf serum and $1 \mathrm{mM}$ pyruvate was used as medium. After 24 hours cells were incubated with BIBW 2992 or for control with dimethylsulfoxid (DMSO). Three days later, cells were irradiated with doses of 2, 4, 6 or $8 \mathrm{~Gy}$. Directly after irradiation $(200 \mathrm{kV} \mathrm{x}$-rays, $0.5 \mathrm{~mm} \mathrm{Cu}, \sim 1$ $\mathrm{Gy} / \mathrm{min}$ ) cells were trypsinised and counted. Appropriately diluted single cell suspensions were incubated in petri dishes for 14 or 10 days (A431), fixed and stained with crystal violet.Colonies with $\geq 50$ cells were scored as survivors. Mean values of the surviving fraction and their standard deviations (SD) were determined for each treatment group and dose level. Cell survival curves were fitted according to the LQ-model. Plating efficiencies (PE) and surviving fractions (SF) were calculated using the following formulas:

$$
\begin{aligned}
& \mathrm{PE}=(\text { colonies } / \text { plated cells }) * 100 \% ; \\
& \mathrm{SF}=(\mathrm{PE} \text { of each dose } / \mathrm{PE} 0 \mathrm{~Gy}) * 100 \% .
\end{aligned}
$$

\section{Results}

Figure 2 shows the relative tumour volume as a function of time after start of treatment for all 5 tumour models. For each of the 4 different treatment arms growth time is presented as the time for tumours to reach the 2-fold $\left(G V_{2}\right)$ and 5 -fold $\left(G V_{5}\right)$ of the starting volume. The application of BIBW 2992 alone leads to a significant prolongation of tumour growth time in all tumour models with considerable intertumoural heterogeneity. While for the A7 tumour model only a slight prolongation of tumour growth can be seen, a distinct effect was observed for the FaDu-, A431-, UT-SCC-14 and UT-SCC15 tumour models. A complete regression of all tumours during continuous application of BIBW 2992 alone without recurrence seen during treatment time (mean 73 days) was determined in the UT-SCC-14, A431 and UT-SCC-15 tumours. During fractionated irradiation (15 fractions within 15 days, total dose $30 \mathrm{~Gy}$ ) a significant prolongation of tumour growth by BIBW 2992 could be observed for the A7, A431 and UT-SCC-15 tumour models where as this effect was not evident in FaDu and UT-SCC-14 tumours (Table 1). The larger growth inhibiting effect of BIBW 2992 alone compared to the combination with fractionated irradiation can be seen as a consequence of the shorter administration within the combined treatment schedule.

Figure 3 depicts the dose response curves for the local tumour control experiment in UT-SCC-15 tumours after fractionated irradiation (30 fractions within 6 weeks) with or without simultaneous application of BIBW 2992. The $\mathrm{TCD}_{50}$ is not significantly altered when BIBW 2992 is added to fractionated irradiation. The $\mathrm{TCD}_{50}$ for irradiation alone is 40.7 Gy [95\% CI: 32;51] and for the simultaneous BIBW 2992 administration 32.2 Gy [18;42] ( $=0.104)$.

Figure 4 illustrates the cell survival curves in vitro for the different cell lines. For the tumour models $\mathrm{FaDu}, \mathrm{A} 431$, UT-SCC-14 and UT-SCC-15 no radiosensitizing effect by incubation with BIBW 2992 could be detected. Only in the A7 glioblastoma cells a slight and for the dose group of 2 and 6 Gy significant radiosenitization could be seen ( $\mathrm{p}$-value for $2 \mathrm{~Gy}=0.050$; p-value for $6 \mathrm{~Gy}=0.046$ ).

Table 2 shows the heterogeneity of the cytotoxic effect of BIBW 2992 on clonogenic tumour cells (plating efficiency, PE) between the 5 cell lines. While there is no effect of incubation with BIBW 2992 on the clonogenicity of A7-, FaDu- and A431 cells, a significant reduction of clonogenic cell survival could be observed for the UT-SCC-14, UT-SCC-15 cells.

\section{Discussion}

The present experiments are the first to test the effect of combined fractionated irradiation and an EGFR/ErbBTK inhibitor on tumour growth time and local tumour control. 4 different squamous cell carcinoma cell lines with heterogeneous radiosensitivity and a radioresistant glioma cell line were selected. We could show a heterogeneous effect on tumour growth time in these 5 different tumour xenografts tested for the administration of BIBW 2992 alone or in combination with fractionated irradiation. These findings are in line with previous experiments, where a prolongation of tumour growth time was seen for the treatment of BIBW 2992 with or without single dose irradiation in the $\mathrm{FaDu}$ tumour model [16] or bladder tumour model [32]. Li et al. [29] also showed an antiproliferative effect on A431 tumour xenografts by a daily oral application of BIBW 2992 alone [29]. The major intertumoural heterogeneity of the antiproliferative effect is in line with previous experience on the selective EGFR-TK inhibitor erlotinib in 5 
Table 1 Time to reach $\mathbf{2}$-fold or $\mathbf{5}$-fold of the starting volume for the five different tumour models and 4 different treatment arms

\begin{tabular}{|c|c|c|c|c|c|}
\hline & Carrier & BIBW 2992 & $15 f / 15 d+$ carrier & & 15f/15d + BIBW 2992 \\
\hline \multicolumn{6}{|c|}{ A7 -Glioblastoma } \\
\hline $\mathrm{GD}_{\mathrm{V} 2}(95 \%$ C.I.) & $6 \mathrm{~d}(6 ; 7)$ & $6.5 d(4 ; 8)$ & $16 \mathrm{~d}(7 ; 48)$ & & $59.5 \mathrm{~d}(24 ; 65)$ \\
\hline ER/p-value & & & & $3.72 / 0.01$ & \\
\hline $\mathrm{GD}_{\vee 5}(95 \%$ C.I.) & $12 \mathrm{~d}(11 ; 13)$ & $16 \mathrm{~d}(13 ; 21)$ & $56 \mathrm{~d}(53 ; 64)$ & & 67 d $(56 ; 72)$ \\
\hline ER/p-value & & & & $1.20 / 0.02$ & \\
\hline \multicolumn{6}{|c|}{ FaDu-SCC from the head and neck } \\
\hline $\mathrm{GD}_{\mathrm{V} 2}(95 \%$ C.I.) & $4 d(3 ; 5)$ & $51 \mathrm{~d}(35 ; 65)$ & $45 \mathrm{~d}(41 ; 48)$ & & $49 \mathrm{~d}(40 ; 52)$ \\
\hline ER/p-value & & & & $1.09 / 0.63$ & \\
\hline $\mathrm{GD}_{\sqrt{ } 5}(95 \%$ C.I.) & $11.5 \mathrm{~d}(10 ; 16)$ & $90 \mathrm{~d}(55 ; 112)$ & $54 \mathrm{~d}(47 ; 64)$ & & $56 \mathrm{~d}(49 ; 63)$ \\
\hline ER/p-value & & & & $1.04 / 0.87$ & \\
\hline \multicolumn{6}{|c|}{ UT-SCC-14 - SCC from the head and neck } \\
\hline $\mathrm{GD}_{\mathrm{V} 2}(95 \%$ C.I.) & $7.5 \mathrm{~d}(6 ; 9)$ & n. a. & $50 \mathrm{~d}(41 ; 103)$ & & $61 \mathrm{~d}(51 ; 85)$ \\
\hline ER/p-value & & & & $1.22 / 0.30$ & \\
\hline $\mathrm{GD}_{\sqrt{ } 5}(95 \%$ C.I.) & $21 \mathrm{~d}(17 ; 26)$ & n. a. & $65 \mathrm{~d}(53 ; 122)$ & & $91.5 \mathrm{~d}(79 ; 111)$ \\
\hline ER/p-value & & & & $1.41 / 0.15$ & \\
\hline \multicolumn{6}{|c|}{ A431-SCC from the cervix } \\
\hline $\mathrm{GD}_{\sqrt{ } 2}(95 \%$ C.I.) & $4.5 \mathrm{~d}(4 ; 7)$ & n. a. & $38 \mathrm{~d}(5 ; 43)$ & & $72 \mathrm{~d}(64 ; 84)$ \\
\hline ER/p-value & & & & $1.89 /<0.0001$ & \\
\hline $\mathrm{GD}_{\sqrt{ } 5}(95 \% \mathrm{CI} . \mathrm{l})$ & $14.5 \mathrm{~d}(9 ; 15)$ & n. a. & $62.5 \mathrm{~d}(52 ; 66)$ & & $122 \mathrm{~d}(64 ; 141)$ \\
\hline ER/p-value & & & & $1.95 / 0.0050$ & \\
\hline \multicolumn{6}{|c|}{ UT-SCC-15 -SCC from the head and neck } \\
\hline $\mathrm{GD}_{\sqrt{ } 2}(95 \%$ C.I.) & $5 d(5 ; 8)$ & n. a. & $34 \mathrm{~d}(15 ; 42)$ & & $56.5 d(48 ; 148)$ \\
\hline ER/p-value & & & & $1.66 / 0.03$ & \\
\hline $\mathrm{GD}_{\sqrt{ } 5}(95 \%$ C.I.) & $16 \mathrm{~d}(14 ; 20)$ & n. a. & $50 \mathrm{~d}(43 ; 100)$ & & $109 \mathrm{~d}(61 ; 182)$ \\
\hline ER/p-value & & & & $2.18 / 0.04$ & \\
\hline
\end{tabular}

ER and p-values in comparison to control groups. n.a. - not applicable (tumours did not reach these endpoints).

different tumour models [8]. With the limitations of a comparison between different experiments, one could conclude that the dual inhibition of EGFR and ErbBreceptor shows no larger effect on the prolongation of tumour growth in the three models treated in both experiments compared to the EGFR-TK inhibitor erlotinib. For UT-SCC-14 and -15 an infinite prolongation with erlotinib or BIBW 2992 could be observed in both experiments. For $\mathrm{FaDu}$, the ER for application of erlotinib was 1.5 for $\mathrm{GD}_{\mathrm{V} 5}$ and for BIBW 2992 an ER of 7.8 for the same endpoint was determined [8]. The latter appears at the first glance as a difference and an advantage for the EGFR-TK inhibitor, but this may well be artificially impacted by the treatment within different experiments.

Local tumour control was evaluated in UT-SCC-15, the cell line with the best response on clonogenic survival after incubation with BIBW 2992 alone in vitro and with the largest effect of the combined treatment on tumour growth in vivo. The A7 cell line showed also a minimal but significant radiosensitizing effect in vitro. However, because of the small amount of this effect and the lower response of this cell line regarding the other endpoints, this was not further followed up. Regarding the effect on local tumour control in UT-SCC-15, there was no benefit seen by the simultaneous ErbB family inhibition with BIBW 2992 during fractionated irradiation

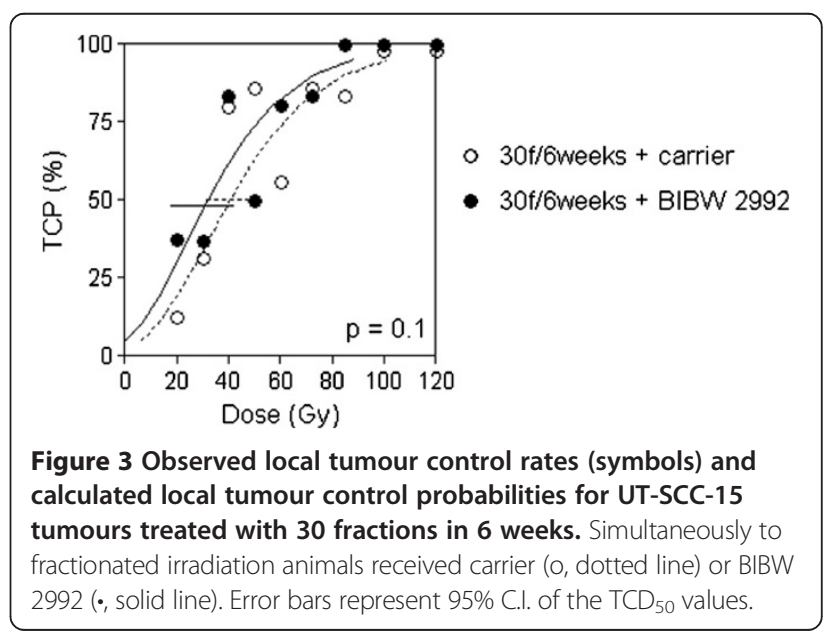



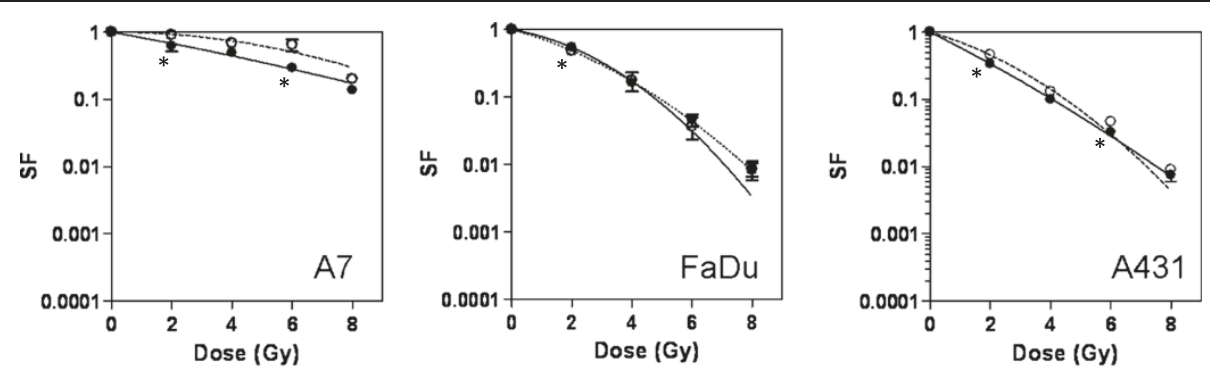

- DMSO

- BIBW2992
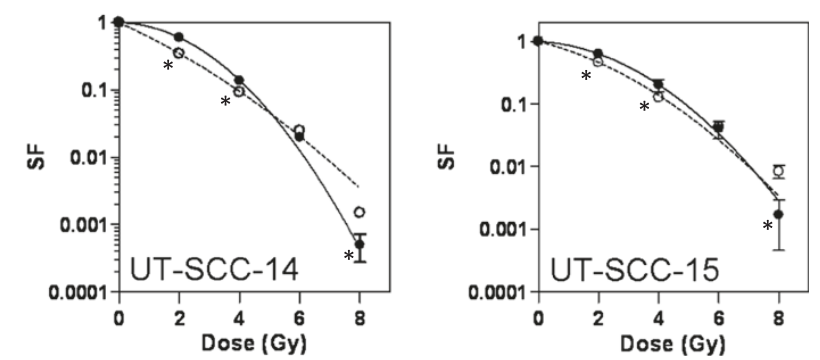

Figure 4 Clonogenic cell survival of A7, A431, FaDu, UT-SCC-14 and UT-SCC-15 cells irradiated with different total doses after three days incubation with normal medium (DMSO; o) or BIBW $2992(\bullet)$, plating directly after irradiation. Symbols and error bars represent means and standard deviations of three independent experiments (duplicates). The data were fitted according to the LQ model (dotted line = normal medium, solid line = BIBW 2992). ${ }^{*}$ significant difference (for dose groups in comparison to control group).

(Figure 3). The $\mathrm{TCD}_{50}$ was not significantly different between fractionated irradiation alone or combined with BIBW 2992. The local tumour control data are comparable to previous experiences where an inhibition of tumour growth by EGFR-TK inhibitors did not translate into an improvement on local tumour control in different tumour models [1,8,28,33].

Animals receiving BIBW 2992 with or without radiation tolerated the drug well (body weight measured weekly as indicator of well being). Common side effects were erythema of the mouth and diarrhea as described before by Schütze et al. [16]. After an application period of approximately 73 days within the first experiment animals started to lose body weight and died or needed to be sacrificed due to reduced general condition. Therefore we reduced the BIBW 2992 dose for the local tumour control experiment to $22.5 \mathrm{mg} / \mathrm{kg}$ b.w.. For early clinical studies on systemic treatment alone (without radiotherapy) the same side effects (erythema and diarrhea) have been observed [34-36] and resemble experiences with other TK-inhibitors like gefitinib or erlotinib $[37,38]$.
It can only be speculated which reasons underly the missing translation of the positive effect on tumour growth into improvement of local tumour control for TK-inhibitors in comparison to antibodies like for example cetuximab. One potential reason could still be an alternative signal transduction. Hu et al. [39] reported a cross talk of the EGFR with the insulin-like growth factor receptor (IGF1R) [39]. Incubating tumour cells with gefitinib or erlotinib led to an increased heterodimerisation of IGF1R and EGFR resulting in a pronounced IGF1R-activation and therefore amplified activation of downstream mediators $[1,40,41]$. In these in-vitro experiments, the induced resistance to EGFRTKI could be overcome by IGF1R-inhibitors $[1,40,41]$. Independent on the biological reasons, the differential effect of BIBW 2992 on tumour proliferation versus local tumour control is finally caused by a missing net effect on cancer stem cells. This is based on the knowledge that all cancer stem cells need to be eliminated to cure a tumour and that a single surviving cancer stem cell after treatment can cause a recurrence, thus making

Table 2 Plating efficiency in vitro after incubation with either normal medium or BIBW 2992 for the $\mathbf{5}$ different cell lines

\begin{tabular}{llllll}
\hline Tumor & A7 & FaDu & UT-SCC-14 & A431 & UT-SCC-15 \\
\hline 0 Gy DMSO (\%) & 5.76 & 19.49 & 5.70 & 30.31 & 9.99 \\
0 Gy BIBW 2992 (\%) & 5.70 & 22.14 & 3.46 & 23.99 & 5.88 \\
ER/p-Wert & $1.01 / 0.9733$ & $0.88 / 0.4274$ & $1.65 / 0.0463$ & $1.26 / 0.2180$ & $1.70 / 0.0005$ \\
\hline
\end{tabular}

Enhancement Ratio (ER) calculated as quotient of $\mathrm{PE}_{\text {normal medium }}$ and $\mathrm{PE}_{\mathrm{BIBW} 2992}$ for each cell line. 
tumour control experiments to an indirect measure of CSC survival in situ [42]. It is interesting to note that BIBW 2992 in vitro does inactivate clonogenic cells in UT-SCC-15 and UT-SCC-14 independent from the irradiation effect (Table 2). If this independent clonogenic cell kill would translate into an inactivation of cancer stem cells in vivo, one would have expected an improvement of local tumour control by the combined treatment. Reasons for the missing translation might be that BIBW 2992 and irradiation preferentially target the same tumour cell population, thus diluting the cytotoxic effect of BIBW 2992 when combining these treatments.

\section{Conclusion}

The present experiments show a heterogeneous effect of the ErbB family TK inhibitor BIBW 2992 on tumour growth in 5 different tumour models for drug application alone as well as in combination with a fractionated radiotherapy. The major effect on tumour growth in UT-SCC-15 tumours did not translate into an improvement of local tumour control. Along with previous experiments on combined fractionated irradiation and EGFR-TK inhibition, it appears likely that TKI do not affect survival of tumour cells that can cause recurrences but can lead to a good palliative effect by proloning tumour growth for a reasonable amount of time.

\section{Competing interests}

The authors declare that they have no competing interests.

\section{Authors' contributions}

KG - carried out in vivo experiments, analysed the data, drafted manuscript. NE - carried out in vivo experiments. DP - carried out and analysed data of the in vitro experiments. WE - validating of the tumours used within experiments (histopathological examination, short tandem repeats, LDH patterns). DZ - conception of experiments. MB - conception of experiments and supervision. MK - conception of experiments, supervision of data analysis and drafting manuscript. All authors read and approved the final manuscript.

\section{Acknowledgements}

The experiments were supported by Boehringer Ingelheim RCV. The authors wish to thank Ms. Katja Schumann, Mrs. Isabell Hillig and Mrs. Elisabeth Jung for excellent technical assistance.

\section{Author details \\ 'Department of Radiation Oncology, UniversityHospital C.G. Carus, Fetscherstr. 74, 01307 Dresden, Germany. ${ }^{2}$ OncoRay - National Centerfor Radiation Research in Oncology, Medical Faculty and University Hospital Carl Gustav Carus, TechnischeUniversität and Helmholtz-Zentrum Dresden - Rossendorf, Dresden, Germany. ${ }^{3}$ Department of Radiation Oncology, University Hospital Tuebingen, Tuebingen, Germany. ${ }^{4}$ German Cancer consortium (DKTK) Dresden and German Cancer Research Center (DKFZ) Heidelberg, Heidelberg, Germany. ${ }^{5}$ Helmholtz-Zentrum Dresden - Rossendorf, Dresden, Germany.}

Received: 2 September 2014 Accepted: 12 November 2014 Published online: 02 December 2014

\section{References}

1. Krause M, Gurtner K, Deuse Y, Baumann M: Heterogeneity of tumour response to combined radiotherapy and EGFR inhibitors: Differences between antibodies and TK inhibitors. Int J Radiat Biol 2009, 85:943-954.
2. Ang KK, Berkey BA, Tu X, Zhang HZ, Katz R, Hammond EH, Fu KK, Milas L: Impact of epidermal growth factor receptor expression on survival and pattern of relapse in patients with advanced head and neck carcinoma. Cancer Res 2002, 62:7350.

3. Nijkamp MM, Span PN, Bussink J, Kaanders JH: Interaction of EGFR with the tumour microenvironment: implications for radiation treatment. Radiother Oncol 2013, 108:17-23.

4. Bonner JA, Harari PM, Giralt J, Azarnia N, Shin DM, Cohen RB, Jones CU, Sur R, Raben D, Jassem J: Radiotherapy plus cetuximab for squamous-cell carcinoma of the head and neck. N Engl J Med 2006, 354:567-578.

5. Bonner JA, Harari PM, Giralt J, Cohen RB, Jones CU, Sur RK, Raben D, Baselga J, Spencer SA, Zhu J: Radiotherapy plus cetuximab for locoregionally advanced head and neck cancer: 5-year survival data from a phase 3 randomised trial, and relation between cetuximab-induced rash and survival. Lancet Onco/ 2010, 11:21-28.

6. Krause M, Ostermann G, Petersen C, Yaromina A, Hessel F, Harstrick A, van der Kogel AJ, Thames HD, Baumann M: Decreased repopulation as well as increased reoxygenation contribute to the improvement in local control after targeting of the EGFR by C225 during fractionated irradiation. Radiother Oncol 2005, 76:162-167.

7. Krause M, Schütze C, Petersen C, Pimentel N, Hessel F, Harstrick A, Baumann M: Different classes of EGFR inhibitors may have different potential to improve local tumour control after fractionated irradiation: a study on C225 in FaDu hSCC. Radiother Oncol 2005, 74:109-115.

8. Gurtner K, Deuse Y, Bütof R, Schaal K, Eicheler W, Oertel R, Grenman R, Thames H, Yaromina A, Baumann M: Diverse effects of combined radiotherapy and EGFR inhibition with antibodies or TK inhibitors on local tumour control and correlation with EGFR gene expression. Radiother Oncol 2011, 99:323-330.

9. Stegeman $\mathrm{H}$, Kaanders JH, van der Kogel AJ, lida M, Wheeler DL, Span PN, Bussink J: Predictive value of hypoxia, proliferation and tyrosine kinase receptors for EGFR-inhibition and radiotherapy sensitivity in head and neck cancer models. Radiother Oncol 2013, 106:383-389.

10. Koi L, Bergmann R, Bruchner K, Pietzsch J, Pietzsch HJ, Krause M, Steinbach J, Zips D, Baumann M: Radiolabeled anti-EGFR-antibody improves local tumor control after external beam radiotherapy and offers theragnostic potential. Radiother Oncol 2014, 110:362-369.

11. Baumann M, Krause M, Dikomey E, Dittmann K, Dorr W, Kasten-Pisula U, Rodemann HP: EGFR-targeted anti-cancer drugs in radiotherapy: preclinical evaluation of mechanisms. Radiother Oncol 2007, 83:238-248.

12. Krause $M$, Baumann M: Clinical biomarkers of kinase activity: examples from EGFR inhibition trials. Cancer Metastasis Rev 2008, 27:387-402.

13. Kong A, Calleja V, Leboucher P, Harris A, Parker PJ, Larijani B: HER2 oncogenic function escapes EGFR tyrosine kinase inhibitors via activation of alternative HER receptors in breast cancer cells. PLoS One 2008, 3:e2881.

14. Rajput A, Koterba AP, Kreisberg Jl, Foster JM, Willson JKV, Brattain MG: A novel mechanism of resistance to epidermal growth factor receptor antagonism in vivo. Cancer Res 2007, 67:665.

15. Toulany M, Minjgee M, Kehlbach R, Chen J, Baumann M, Rodemann HP. ErbB2 expression through heterodimerization with erbB1 is necessary for ionizing radiation-but not EGF-induced activation of Akt survival pathway. Radiother Oncol 2010, 97:338-345.

16. Schütze C, Dörfler A, Eicheler W, Zips D, Hering S, Solca F, Baumann M, Krause M: Combination of EGFR/HER2 tyrosine kinase inhibition by BIBW 2992 and BIBW 2669 with irradiation in FaDu human squamous cell carcinoma. Strahlenther Onkol 2007, 183:256-264.

17. Yaromina A, Zips D, Thames HD, Eicheler W, Krause M, Rosner A, Haase M, Petersen C, Raleigh JA, Quennet V: Pimonidazole labelling and response to fractionated irradiation of five human squamous cell carcinoma (hSCC) lines in nude mice: the need for a multivariate approach in biomarker studies. Radiother Oncol 2006, 81:122-129.

18. Eicheler W, Krause M, Hessel F, Zips D, Baumann M: Kinetics of EGFR expression during fractionated irradiation varies between different human squamous cell carcinoma lines in nude mice. Radiother Oncol 2005, 76:151-156.

19. Petersen C, Zips D, Krause M, Volkel W, Thames HD, Baumann M: Recovery from sublethal damage during fractionated irradiation of human FaDu SCC. Radiother Oncol 2005, 74:331-336.

20. Krause M, Hessel F, Zips D, Hilberg F, Baumann M: Adjuvant inhibition of the epidermal growth factor receptor after fractionated irradiation of FaDu human squamous cell carcinoma. Radiother Oncol 2004, 72:95-101. 
21. Gurtner K, Hessel F, Eicheler W, Dörfler A, Zips D, Heider K, Krause M, Baumann M: Combined treatment of the immunoconjugate bivatuzumab mertansine and fractionated irradiation improves local tumour control $<\mathrm{i}>$ in vivo</i $>$. Radiother Oncol 2012, 102:444-449.

22. Eicheler W, Zips D, Dörfler A, Grénman R, Baumann M: Splicing mutations in TP53 in human squamous cell carcinoma lines influence immunohistochemical detection. J Histochem Cytochemistry 2002, 50:197.

23. Baumann M, DuBois W, Pu A, Freeman J, Suit HD: Response of xenografts of human malignant gliomas and squamous cell carcinomas to fractionated irradiation. Int J Radiat Oncol Biol Phys 1992, 23:803-809.

24. Hessel F, Krause M, Helm A, Petersen C, Grenman R, Thames HD, Baumann M: Differentiation status of human squamous cell carcinoma xenografts does not appear to correlate with the repopulation capacity of clonogenic tumour cells during fractionated irradiation. Int J Radiat Biol 2004, 80:719-727.

25. Zietman AL, Suit HD, Ramsay JR, Silobrcic V, Sedlacek RS: Quantitative studies on the transplantability of murine and human tumors into the brain and subcutaneous tissues of NCr/Sed nude mice. Cancer Res 1988, 48:6510

26. Yaromina A, Krause M, Thames H, Rosner A, Krause M, Hessel F, Grenman R, Zips D, Baumann M: Pre-treatment number of clonogenic cells and their radiosensitivity are major determinants of local tumour control after fractionated irradiation. Radiother Oncol 2007, 83:304-310.

27. Yaromina A, Thames H, Zhou X, Hering S, Eicheler W, Dorfler A, Leichtner T, Zips D, Baumann M: Radiobiological hypoxia, histological parameters of tumour microenvironment and local tumour control after fractionated irradiation. Radiother Oncol 2010, 96:116-122.

28. Krause M, Prager J, Zhou X, Yaromina A, Dörfler A, Eicheler W, Baumann M: EGFR-TK inhibition before radiotherapy reduces tumour volume but does not improve local control: differential response of cancer stem cells and nontumourigenic cells? Radiother Oncol 2007, 83:316-325.

29. Li D, Ambrogio L, Shimamura T, Kubo S, Takahashi M, Chirieac L, Padera R, Shapiro G, Baum A, Himmelsbach F: BIBW2992, an irreversible EGFR/HER2 inhibitor highly effective in preclinical lung cancer models. Oncogene 2008, 27:4702-4711.

30. Solca F, Dahl G, Zoephel A, Bader G, Sanderson M, Klein C, Kraemer O, Himmelsbach F, Haaksma E, Adolf GR: Target binding properties and cellular activity of afatinib (BIBW 2992), an irreversible ErbB family blocker. J Pharmacol Exp Ther 2012, 343:342-350.

31. Walker AM, Suit HD: Assessment of local tumor control using censored tumor response data. Int J Radiat Oncol Biol Phys 1983, 9:383-386.

32. Tsai Y, Yeh C, Tzen K, Ho P, Tuan T, Pu Y, Cheng A, Cheng JC: Targeting epidermal growth factor receptor/human epidermal growth factor receptor 2 signalling pathway by a dual receptor tyrosine kinase inhibitor afatinib for radiosensitisation in murine bladder carcinoma. Eur J Cancer 2013, 49:1458-1466.

33. Baumann M, Krause M, Zips D, Eicheler W, Dörfler A, Ahrens J, Petersen C, Brüchner K, Hilberg F: Selective inhibition of the epidermal growth factor receptor tyrosine kinase by $\mathrm{BIBX} 1382 \mathrm{BS}$ and the improvement of growth delay, but not local control, after fractionated irradiation in human FaDu squamous cell carcinoma in the nude mouse. Int J Radiat Biol 2003 , 79:547-559.

34. Eskens F, Mom C, Planting A, Gietema J, Amelsberg A, Huisman H, van Doorn L, Burger H, Stopfer P, Verweij J: A phase I dose escalation study of BIBW 2992, an irreversible dual inhibitor of epidermal growth factor receptor 1 (EGFR) and 2 (HER2) tyrosine kinase in a 2-week on, 2-week off schedule in patients with advanced solid tumours. Br J Cancer 2008, 98:80-85.

35. Yap TA, Vidal L, Adam J, Stephens P, Spicer J, Shaw H, Ang J, Temple G, Bell S, Shahidi M, Uttenreuther-Fischer M, Stopfer P, Futreal A, Calvert H, de Bono JS, Plummer R: Phase I trial of the irreversible EGFR and HER2 kinase inhibitor BIBW 2992 in patients with advanced solid tumors. J Clin Oncol 2010, 28:3965-3972.

36. Yang JC, Shih J, Su W, Hsia T, Tsai C, Ou SI, Yu C, Chang G, Ho C, Sequist LV: Afatinib for patients with lung adenocarcinoma and epidermal growth factor receptor mutations (LUX-Lung 2): a phase 2 trial. Lancet Oncol 2012, 13:539-548.

37. Mitsudomi T, Morita S, Yatabe Y, Negoro S, Okamoto I, Tsurutani J, Seto T, Satouchi M, Tada H, Hirashima T: Gefitinib versus cisplatin plus docetaxel in patients with non-small-cell lung cancer harbouring mutations of the epidermal growth factor receptor (WJTOG3405): an open label, randomised phase 3 trial. Lancet Oncol 2010, 11:121-128.

38. Rosell R, Carcereny E, Gervais R, Vergnenegre A, Massuti B, Felip E, Palmero R, Garcia-Gomez R, Pallares C, Sanchez JM: Erlotinib versus standard chemotherapy as first-line treatment for European patients with advanced EGFR mutation-positive non-small-cell lung cancer (EURTAC): a multicentre, open-label, randomised phase 3 trial. Lancet Oncol 2012, 13:239-246.

39. Hu YP, Patil SB, Panasiewicz M, Li W, Hauser J, Humphrey LE, Brattain MG: Heterogeneity of receptor function in colon carcinoma cells determined by cross-talk between type I insulin-like growth factor receptor and epidermal growth factor receptor. Cancer Res 2008, 68:8004.

40. Morgillo F, Woo JK, Kim ES, Hong WK, Lee HY: Heterodimerization of insulin-like growth factor receptor/epidermal growth factor receptor and induction of survivin expression counteract the antitumor action of erlotinib. Cancer Res 2006, 66:10100.

41. Morgillo F, Kim WY, Kim ES, Ciardiello F, Hong WK, Lee HY: Implication of the insulin-like growth factor-IR pathway in the resistance of non-small cell lung cancer cells to treatment with Gefitinib. Clin Cancer Res 2007 13:2795-2803

42. Baumann M, Krause M, Thames H, Trott K, Zips D: Cancer stem cells and radiotherapy. Int J Radiat Biol 2009, 85:391-402.

doi:10.1186/s13014-014-0261-z

Cite this article as: Gurtner et al:: Effect of combined irradiation and EGFR/Erb-B inhibition with BIBW 2992 on proliferation and tumour cure in cell lines and xenografts. Radiation Oncology 2014 9:261.

\section{Submit your next manuscript to BioMed Central and take full advantage of:}

- Convenient online submission

- Thorough peer review

- No space constraints or color figure charges

- Immediate publication on acceptance

- Inclusion in PubMed, CAS, Scopus and Google Scholar

- Research which is freely available for redistribution 